a knowledge of the constitution of the ether which we do not possess. We now assume that the ether is not set in motion by an electro-magnetic wave. If we do equation quantities representing the components of the tion of the the ether, and unless we know the constituties from the forces acting on it, there will be in the equations of the electro-nagnetic field more unknown quantities than we have equations to determine. It is,
therefore, a very essential point in electro-magnetic theory to investigate whether or not there is any mo-
tion of the ether in a varying electro-magnetic field. tion of the ether in a varying electro-magnetic field.
We have at the Cavendish Laboratory, using Prof. Lodge's arrangement of interference fringes, made some experiments to see if we could detect any movement of
the ether in the neighborhood of an electric vibrator, using the spark which starts the vibrations as the
source of light. The movement of the ether, if it exists, source of light. The movement of the ether, if it exists,
will be oscillatory, and with an undamped vibrator the will be oscillatory, and with an undamped vibrator the locity might be expected to be finite. The experiments negative. We also tried by the same method to see if we could detect any movement of the ether. in the neighborhood of a vacuum tube emitting Roentgen
rays, but could not find any trace of such a movement. priment, has, I believe, arrived at the the same exsion.
Unless the ether is immovable under the mechanica forces in a varying electro-magnetic field, there are multitude of phenomena a waiting discovery. If the electrical vibrations, and therefore of light, will be if containing nothing but ether, will behave toward light like a crystal, and the velocity of propagation will depend upon the direction of the rays. A sinilar
result would also hold in a steady electric field. We may hope that experiments on these and similar points which is ume light on the properties or that medium explanation of physical phenomena, and of which we

THE ACTION OF LIGHT UPON

$$
\text { PERFUMES. }
$$

IN a preceding article we described a process de-
vised by Mr. E. Mesnard for comparing the intensity of vised by Mr. E. Mesnard for comparing the intensity of
perfumes. The same investigator has endeavored to produce an apparatus that should be less delicate and more easily transportable, and that should give just as
accurate results. The model that he has decided upon
is very ingenious. We shall give a brief deseription of is very ingenious. We shall give a brief description of
it, as seen by us in operation at M. Gaston Bonnier's In an oblong box provided with a hinged cover (Fig.

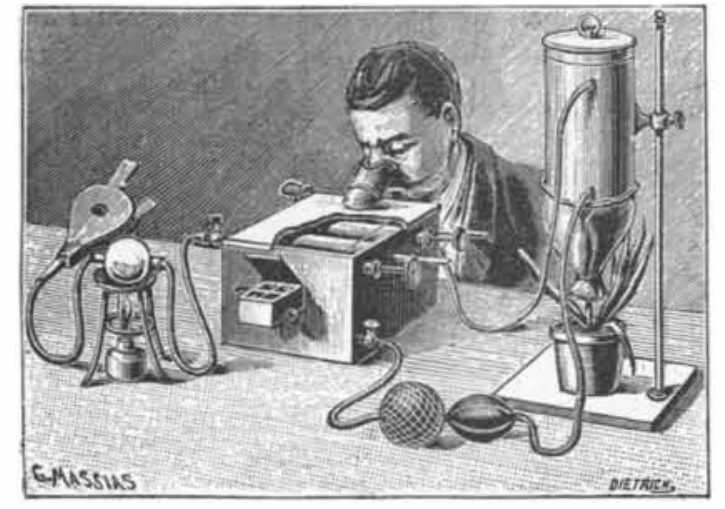

Fig. 1.-APPARA'TUS FOR COMPARING ODORS.

1) there are arranged two parallel cylinders of fine wire cylinder is maneuvered from the exterior by means of a
winch placed at one of the extremities of the axis. The winch placed at one of the extremities of the axis. The
other extremity of this axis carries a graduated disk
which inoves alone a fixed rule that is likewise graduated. It is possible in this way to estimate the number of revolutions and

It is in the oblong box that the odors are mixed. To this effect there is placed externally a framie divided grooved pulley over which passes a thread. 'This thread thoroughly saturated with the essential oil, is dried by
its passage through a wad of cotton, enters the box through a very small orifice and afterward winds around one of the cylinders.

By this arrangement, it is therefore possible, at one's
wili, to cause a certain length of thread inupregnated with essential oil to wind up in the box, or else to cause
the thread that was first inclosed in the frame to reenter the latter in order to become saturated anew. It will be readily understood that upon winding a greate
or less length of thread around the cylinder, there is introduced into the box a quantity of essential oil that is proportional to the length of the thread wound.

proportional to the length of the thread wound.
The cover is provided with an orifice surmounted by
a cone that has exactly the form of the nose and permits a cone that has exactly the form of the nose and permits of obtaining a smell of the interior when a valve is
opened through a pressure upon a small button proopened through a pressure upon a small button pro-
perly arranged. If it is a question of comparing two the unknown oil and the other with spirit of turpen-
tine taken as a standard, and an endeavor is made to ascertain what length of this latter thread must be in-
troduced into the box in order to produce upon the olfactory membrane an odoriferous intensity equiva
lent to that which is produced by a given length of lent to that which is produced by a given length
thread impregnated with the unknown essential oil. This therefore amounts, upon the whole, to the sam thing as measuring the intensity of a perf ume with a meter measure. The model just described is especially perfumes. If it is desired to experiment upon a

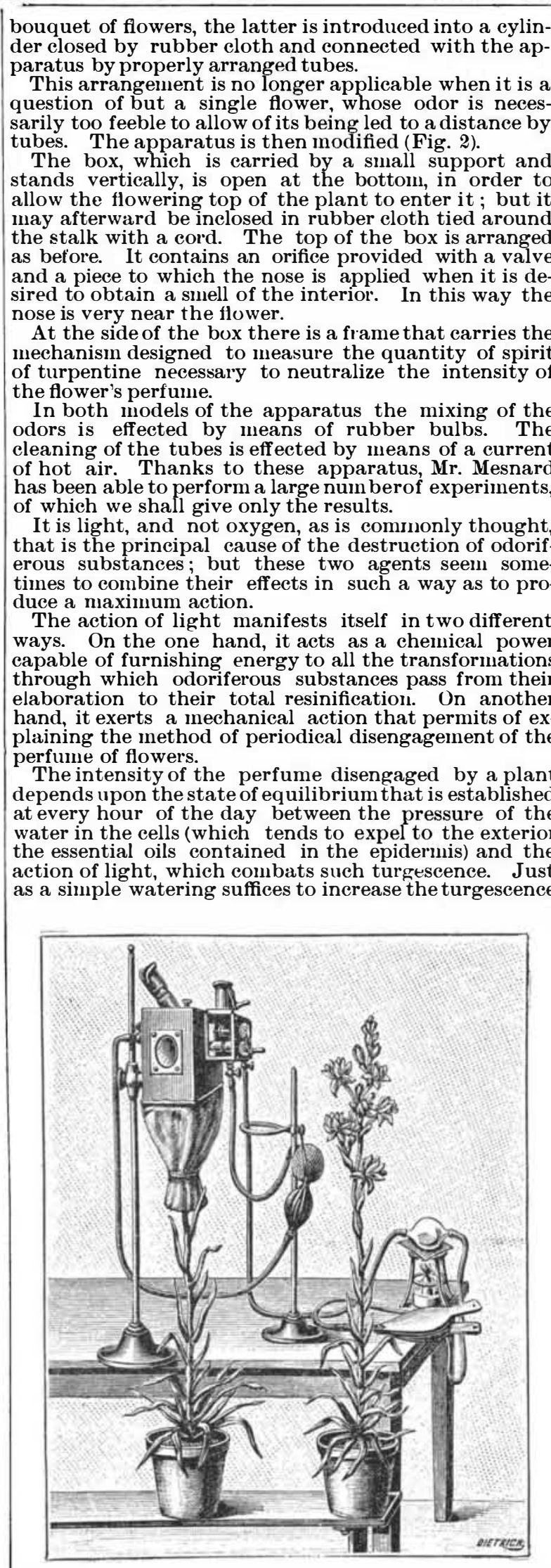

Fig. 2.-APPARATUS FOR MEASURING THE INTENSITY OF PERFUMES.

f the cells, so the interposition of a simple glass screen, the presence of a cloud or the advent of cloudy or rainy by light. In both cases the intensity of the perfume In reality, it is the irritabilit y of the protoplasm that is the primordial cause of the variation in intensity of
the perfune of flowers. and experiment proves that a
sudden insolation or simple contact suffices to provoke such irritability, and consequently to bring about a plant and an aimost sudden increase of the intensity of The perfume.

The alternations of day and night determine maxi which are often modified, it is true, by the changeable ness of the weather, but which nevertheless bring There are sone plants that are more sensitive than others, certain orchids, for example, in which such
periodicity occurs in a much more niarked manner. pariodicity occurs in a much more mar
Lature.

By J. J. Stewart, B.A. Cantab., B.Sc. Lond., in Knowledge.

ThE beauty of the objects of nature around us depends so much on the varieties of color which they exof the blue sky, the green foliage, and the various splendors of flowers and fruits to realize to how great try scene is due to the many-hued surfaces of natural
objects. The pleasurable feelings aroused by the sight objects. The pleasurable feelings aroused by the sight
of the deep blue of the sea contrasting with the bright ed color of the sandstone cliffs, or the effect of the heather on the slopes of the hills, can be forgotten by none who have experienced them: and the striking
effect of Eastern scenes is owing largely to the brilliance of the tints which meet the eye. It is needles
ling to enlarge on the part played by color in this world of
ours; the difference between a world of color and one n which surrounding objects were only distinguished y different shades of gray can be realized by all. a rose is produced, and why it differs in appearance from a blue flower, we must consider what happens to the light which falls upon the petals of the rose. We see the flower because the light from the sun is reflect-
ed from it, but something has happened to the light before it reaches our eyes : the light we receive differs
from that which fell upon the flower. The rays from from that which fell upon the flower. The rays from
the sun penetrate to a certain extent into the subthe sun penetrate to a certain extent into the sub-
stance of the flower, and most of them are reflected from particles beneath the surface. Now the cells making up the petals of a rose contain a fluid which
has the power of absorbing certain of the rays of light and the light entering the eye after penetrating a short distance below the surface of the petals and coming
back has passed through this fluid, and in its course back has passed through this fluid, and in its course
some of the rays of the sunlight have been abstracted rom it. Thus the light reaching us is lacking in certain of the constituents of white light-that is, it is
colored. White light may be considered as made up of the three fundamental colors, red, green and violet blended together. The light which has passed through
a certain extent of the substance of the rose petals has a certain extent of the substance of the rose petals has thus the red rays alone reach our eyes. All substances which possess color exercise this power of sifting the which possess color exercise this power of sifting the
rays of light. Light falling on the leaves of the rose bush passes through their superficial layers and is reflected from below the surface; thus it has to traverse certain particles which take from it the red and violet
rays and allow the green to pass. The green rays reach our eyes, and we therefore call the leaves green When white light passes through a prism it is found that in the band of color or spectrum produced, the blue and violet rays are the most bent out of their
original course; they are the most refrangible. The red rays are the least bent. It is found, also, that the waves of light are quickest in violet light and slowest in red light. Some substances absorb the quick vibrations more readily and thus appear reddish in color.
Others absorb the slower vibrations, allowing the others to pass through, and therefore have a green or When a substance is heated its particles are thrown
Whelor. into a state of rapid motion, and soon set up a motion in the ether which, when the vibrations are of a certain rapidity, produces light. If a ball of iron is heatrays, which have the effect of producing heat. As its
particles become hotter and hotter, and thus vibrate more rapidly, the radiation begins to affect our eye of greater and greater rapidity take place owing to the further heating, the ball appears bright yellow, and pidities which affect our eyes are given out. In this
case it is the motion of the particles or molecules of the heated body which is imparted to the ether, and so produces the effect we call light. Now those mole give them to the ether absorb these same vibrations from the ether-that is, absorb certain rays of light.
This effect is best seen in the case of gases, and the phenomenon is analogous to that which occurs with a certain note when it is struck is able to take up and absorb the note from the vibrating air around it when
that note is sounded in its neighborhood.

It may be noticed that the light from the electric arc When near at hand has a distinctly bluish color pears yellowish, as certain of its rays have been abthe eye. For a similar reason the sun is now considertensely white, and rich in blue rays especially, if it could be seen from beyond our atmosphere, appears and has lost some of its most refrangible constituent The effect of absorption in producing color is seen rom the fact that powdered bodies generally appear
white. This is accounted for when we consider that powder consists of particles arranged at all angles, so that the light falling upon it meets various surfaces and is mostly reflected before it has passed below the
surface. Thus the white light reaching it is not deprived of some of its constituents by selective absorpwas then reflected. In this way powdered red glass apiquids, such as brown ale, appears pure white. The bubbles, and does not pass much through the liquid itself. Thus also a cloud is very opaque to light, the
light falling on it being reflected at the surface of the numerous globules of water. To this is due the brilliantly white appearance of large fleecy clouds in bright Some substances absorb equally all the rays of light. Such substances, of which soot is an example, appea black. The reason why a flower like a white lily ap-
pears white is that the fluid contained in its cells does not absorb one sort of rays more than another but below, is not deprived of any of its constituents, but reThe eff ect of reflection from internal surfaces, accompanied by absorption in producing color, can be seen ing particles, into a white porcelain basin. Light is reliquid, and its color is seen. If now the sides of the
iquing basin be covered with some black substance, no light will be reflected from them and the liquid will appear the surface of the liquid reflects all the rays equally. powder like chalk, its color is at once restored, light being now reflected from the interior at the surfaces of From the above considerations we can understand
the chalk particles. 
to what causes the color produced on mixing pigments for days after having lost the whole abdomen, with the after day, and often at night also. Rooms and entries of is due. A mixture of blue and yellow paints has a viscera, separate legs, wings or other parts of the body country dwellings, cellars, garrets, and stables are fa-
green color because that is the only color transmitted of which they have been deprived by being stepped vorite places of abode for these spiders. Those I
verse by both pigments. The blue paint absorbs the red, on by a careless pedestrian Ourlong-legred phalangium watched were in a room which had been used for the

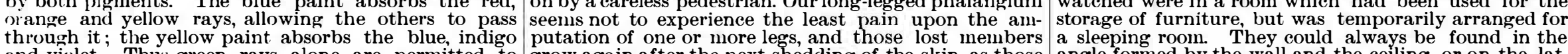
and violet. Thus green rays alone are permitted to appears of that color. by reflected light, and another when seen by transmitted light. Thus the light reflected by gold is yellow; but a leaf of gold made so thin that light can pass
through it appears of a green color. This appearance of different colors on reflection and transmission is also light due which are not admitted at all, but sent back at the surface, together with that light which has been reflected from a certain depth below the surface, and has sorption. The light to which the color is due when the substance is viewed by light which has passed rays by reflection at the first surface, and again of others by absorption in passing through. Hence the ways.
Variations in color perception no doubt depend on varying sensations in our own eyes, as well as on have been made with a view to testing our different sensations as to color. It has often been noticed that a good photographic dark room with ruby glass windescribed recently in Berlin some experiments he had described recently in Berlin some experiments he had
made. He used oil lamps and fitted on to them pure when the white light was entirely shut out no tha color was perceptible to the observers, and objects in the room appeared of various shades of black and white. Ho found that when a set of colors was lit up
by red light the red pigments appeared white or gray, by red light, the red pigments appeared white or gray, when blue was ad-led to the light under which they not exist in either of the sources of light used. The
color sensation produced by a source of light also depends partly on the intensity of the illumination. to the conclusion that our opinion as to the color of piginent depends upon our perception of the absence Thus a surface which has a red color is only perceived as red by us when light of other colors shines upon it, and we observe its incapacity for reflecting these colors. remarkable blue shimmer is noticed extending for a short diste substances, the color being different in different cases. The phenomenon is known as fluorescence, as it is well observed in the mineral fluorspar, and is due to the fact that light is absorbed by the substance and is again given out as light of a different color. For inof the spectrum may be taken in and given out as yelnine, invisible rays beyond the violet are absorbed and blue or violet rays are emitted by the solution. In all cases of fluorescence a degradation of the rays takes place; those given out are of lower refrangibility than screen with a solution of sulphate of quinine, the specvibrations which are too rapid to affect our eyes are changed into others of lower refrangibility, which can be perceived when they fall on the retina. The curious blue color of the solution of quinine extends only a
short distance into the liquid, because those rays which short distance into the liquid, because those rays which are capable of producing it are soon absorbed, and the
light which passes onward through the fluid is destirescence has a different origin from that of the ordinary surface color of substances, for the rays absorbed do not disappear as light, but their place is taken by other rays of a different sort.

The nature of the vibrations which constitute light made in recent years in our acquaintance with these and allied phenomena, and we may hope for still greater accessions to our knowledge in the not distant
future.

\section{SOME INTERESTING SPIDERS} By Prof. Franz Mulleter.

W но does not know the common shepherd spider that moves about in such ghostly fashion on its long, slentained by the grotesque movements of the perfectly
harmless creature. This phalangium, although related harmless creature. This phalangium, although related but in place of the poison fangs of real spiders, it is
provided with downwardly bent scissorslike palpi, by provided with downwardly bent scissorslike palpi, by
means of which it eatches little insects and carries them to its mouth. It is so well known that it needs no descript:on, but an enumeration of the characteris-
ties which distinguish it from other spiders may be of interest: These are the filiform maxillary palpi termishaped abdomen, and the small number of its eyes-
for it has only two simple eyes. These spiders prefer to spend the day grouped together in dark corners and nooks, and if one of them is touched lignitly, it begins
to rock or swing its body. This motion is imitated by those near it and soon the whole company are making quiet again. If touched more roughly or caught, they try to escape, even if obliged to leave behind one or
more of their legs. As every one knows, these legs that have been torn off keep up a fluttering motion for nervous system found in all articulated animals, which causes single dismembered portions of the body to show
signs of life for a long time; but, in all probability, there
is no conscious feeling. Oue may, for instance, see grow again after the next shedding of the skin, as those
of the crab do under similar circumstances. The whitof the crab do under similar circumstances. The whit-
ish eggs are laid by the female in damp places, where The swinging or swaying motion adopted by the phalangium when slightly disturbed is not peculiar to it cross spider is approached in warm weather. when in is moved slightly, it begins to swing so energetically web. This occurrence can easily be observed in sum mer in a sunny grove of young trees, where hundreds of
these beautiful webs are spread. The object the creature has in making these strange movements it is not difficult to guess, for it must be the same as that of silkger threatens, draw in their heads or take a defensive attitude, which is indicated by the forms and colors they assume. When a cat crooks her back upon the teeth and sharp claws, she does it for the same reason, viz., to frighten the assailant.

A certain spider has been called the "trembling" to its dwelling. Several specimens are shown on a some a sleeping room. They could always be found in the angle formed by the wall and the ceiling, or on the lat-
ter but never far from the wall. Like the shepherd spider, they remain quiet and motionless, apparently wander very far, for in the morning they are always to be found in the same place. The reason for this is that their nets are there, stretched between rough places in
the wall. They are scarcely visible, but upon looking closely, their presence is betrayed by the little flies and particles of dust which have been caught in thens. If one its droll swaying motion, and then it can easily be seen that it is holding onto the threads by its long, slender live struggling fly is held in the web, the spider is From all that I have beent motion and takes flight. Feems to hve entirely on able to observe, the pholcus the shepherd spider, catches by spreading its long legs and running over it. One night I saw many tiny flies them reached the domain of my spider. By making a sudden movement to that side of the web where the spider caught his victin as quick as lightning, the sucked its life out.

The swaying motion of one of these spiders is accom-

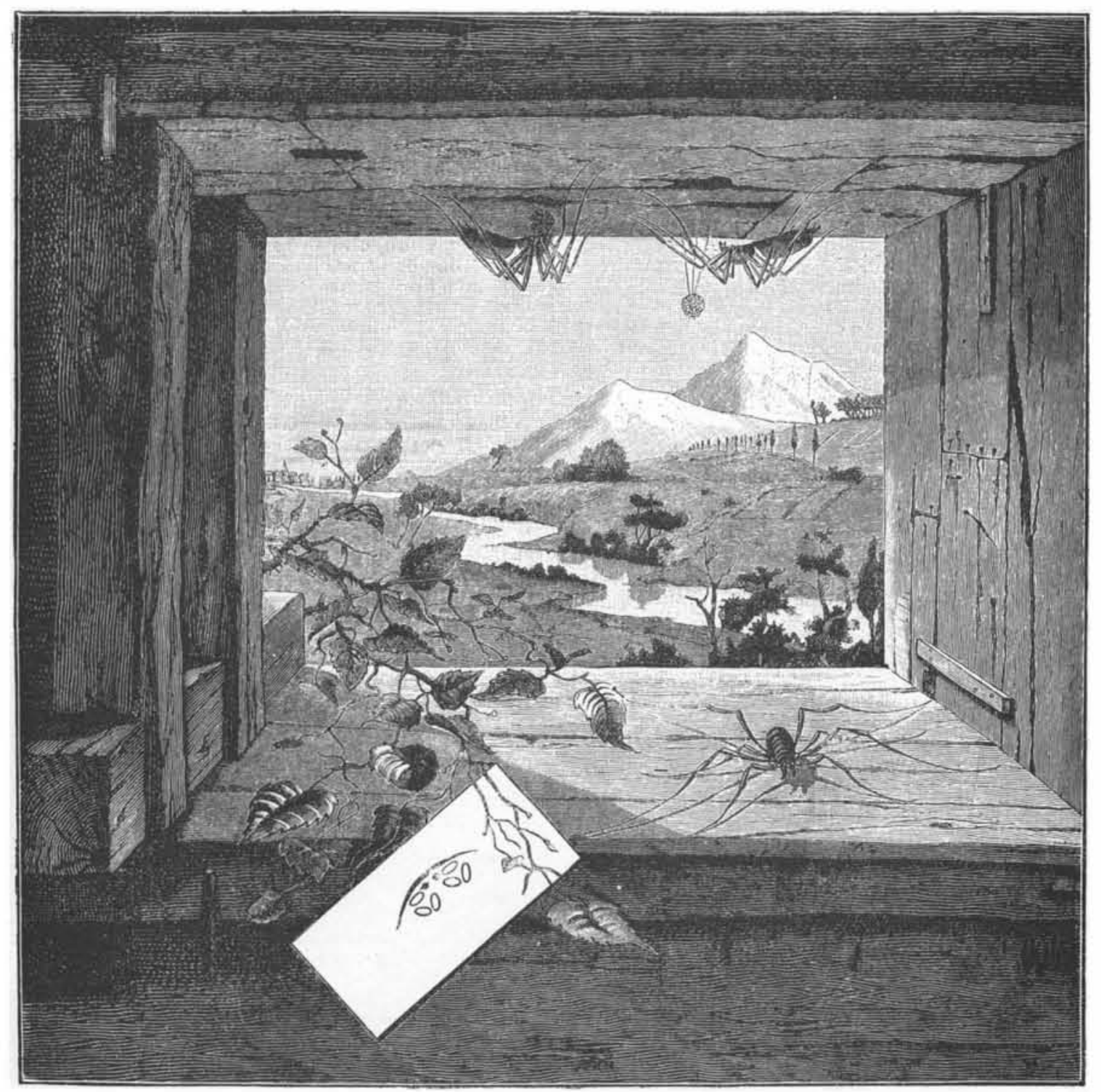

PHALANGIUM AND PHOLCUS.

Above at the left is a pholcus carrying its cocoon; at the right the cocoon is suspended. Below at the right a phalangium, at the left a white field showing the position of the eyes of the pholcus.

and as their habits of life are interesting. which perhaps $\mid$ plished by placing its long legs on separate threads of some of our readers may have had as favorable oppor- the web or on rough places in the wall and moving it more closely. This "trembling" spider is also called the ticity of its feet and of the threads of the web, the mo"squinting" spider (pholcus, from the Greek pholkos, or tion finally becomes so rapid that the body of the spider squinting, which name was given it on account of the can scarcely be seen. This performance is most interpeculiar shape and position of its eight eyes (see lower esting, and a spider never tires of repeating it, whenpach side which differ from those of other spidersiped on oval and milky white, with black edges, which gives the smaller and solid black. The creature is slender and the cephalo-thorax, which carries its long, delicate, hairy legs, seems almost round when looked down upon:
its abdomen is rather long and almost cylinder shaped, and its front legs are nearly six times as long as its enIn regard to the geographical distribution of to take it up carefully, it freed itself by a sudden jerk lands, France, Italy, Sweden, Hungary, and in some it swung gayly in a circle with its five feet, as if it had localities in upper and lower Austria. Strangely suffered no inconvenience. Unfortunately, I could
enough, it and all other spiders of the same family never know whether the lost legs grew again, for, greatly (Phocid, are very numerous in East India, lamily tudents have come to the conclusion that this spider and, but acrom that

The habits of animals of all kinds ean best be learne ay watching them when free, for in captivity they genthey had been left in their natural state. This seem to be particularly true in regard to spiders. I once hac is no conscious feeling. Oue may, for instance, see an opportunity, during a stay of eight weeks at Mondsee
wasps, May bugs, and other insects running around
of watching nine of these interesting little creatures day ever disturbed by a slight 1 .
only when roughly disturbed.

Both of the spiders which we have been describing ractice another ruse, which seems to be quite common to many other creatures higher and lower-that is fere uddenly as if it had thought of somethin topter tretched out its legs and lay as if dead. When I wanted Another characteristic which adds to the interest of watching these spiuers is the special care manifeste by the female for her offspring It is well known that spiders place their eggs in a cocoon. In winter one as a hazel nut, hanging on the wall, in the windows, be in sin the about with about with egg sacs fastened under the thorax by slen-
der threads. If relieved of their precious burdens, they 